\title{
PENGARUH IKLIM KELAS KONDUSIF DALAM PEMBELAJARAN \\ IPS TERHADAP HASIL BELAJAR SISWA KELAS VIII DI SMP N 2 BUAY MADANG TIMUR
}

\author{
Wiastuti Rahayu Ningsih ${ }^{1}$, Mursilah ${ }^{2}$, Vovi $\operatorname{Sinta}^{3}$ \\ ${ }^{1,2,3}$ Program Studi Pendidikan Ekonomi STKIP Nurul Huda \\ *E-mail: Rahayuningsih@mail.com
}

\begin{abstract}
Abstrak: Penelitian ini bertujuan untuk mengetahui pengaruh iklim kelas kondusif dalam pembelajaran IPS terhadap hasil belajar siswa kelas VIII di SMP N 2 Buay Madang Timur, penelitian ini termasuk penelitian deskriptif kuantitatif dengan menggunakan metode eksperimen (posttest only control design). Populasi dari penelitian ini adalah seluruh siswa kelas VIII SMP N 2 Buay Madang Timur yang berjumlah empat kelas. Teknik pengambilan sampel dalam penelitian ini menggunakan dua kelas dipilih secara random dari populasi dilakukan secara acak tanpa memperhatikan strata yang ada dalam populasi itu. Teknik pengumpulan data yang digunakan dalam penelitian ini adalah angket dan tes, pengujian hipotesis nya menggunakan uji t. Berdasarkan hasil dari analisis data dapat disimpulkan bahwa terdapat pengaruh yang signifikan antara iklim kelas kondusif dalam pembelajaran IPS terhadap hasil belajar siswa kelas VIII di SMP N 2 Buay Madang Timur. Yang dibuktikan dengan hasil uji $\mathrm{t}$ dengan $\mathrm{dk}=40$ angka derajat kebebasan $\mathrm{t}_{\text {tabel }}$ taraf signifikan $5 \%=1,68$ menunjukkan bahwa $t_{\text {hitung }}>t_{\text {tabel }}$ yaitu 4,83 $>1,68$.
\end{abstract}

Kata Kunci: Iklim Kelas Kondusif, Hasil Belajar, IPS.

\section{PENDAHULUAN}

Belajar sangat penting dalam kehidupan setiap individu terutama sebagai Peseta didik. Namun belajar tidak selalu menyenangkan bagi beberapa Peserta didik (Oscar, 2014). Pembelajaran suatu proses yang rumit karena tidak sekedar menyerap informasi dari guru, tetapi juga melibatkan berbagai kegiatan dan tindakan yang harus dilakukan untuk mencapai hasil belajar yang baik (Novan, 2014). Guru bertanggung jawab untuk mengatur, mengarahkan, dan menciptakan suasana yang mendorong siswa untuk melaksanakan kegiatan-kegiatan di kelas (Nur, 2016).

Undang-Undang Republik Indonesia nomor 20 tahun 2003 tentang sistem pendidikan nasional (2011:6) pasal 3, yaitu: 


\begin{abstract}
"Pendidikan nasional berfungsi mengembangkan kemampuan membentuk watak serta peradaban bangsa yang bermartabat dalam rangka mencerdaskan kehidupan bangsa, bertujuan untuk berkembangnya potensi peserta didik agar menjadi manusia yang beriman dan bertakwa kepada Tuhan Yang Maha Esa, berahlak mulia, sehat, berilmu, cakap, kreatif, mandiri dan menjadi warga negara yang demokratis serta bertanggung jawab".
\end{abstract}

Proses pembelajaran merupakan salah satu faktor yang sangat berpengaruh terhadap pencapaian mutu pendidikan, dalam hal ini guru dituntut mampu menyelenggarakan kondisi pembelajaran yang efektif (Musfida, 2017). Menurut Sanjaya (2015) Pembelajaran yang efektif tidak hanya diukur dari kemampuan guru dalam menyampaikan materi pembelajaran sehingga siswa mudah memahami dan menguasai berbagai kompetensi yang diharapkan. Melainkan juga kemampuan guru dalam mengelola iklim kelas yang kondusif yaitu suasana yang nyaman dan menyenangkan, sehingga mendukung keberhasilan siswa dalam proses pembelajaran. Fieteriani (2015) berpendapat bahwa Suasana kelas yang menyenangkan mampu juga memberi semangat kepada siswa untuk belajar.

Dilihat dari peranan guru sebagai seorang pendidik, pembimbing, pelatih, dan pemimpin yang dapat menciptakan iklim kelas yang menarik, aman, nyaman dan kondusif, keberadaanya di tengah-tengah siswa dapat mencairkan suasana kebekuan, kekakuan dan kejenuhan belajar yang terasa berat diterima oleh para siswa. Iklim kelas yang tidak kondusif akan berdampak negatif terhadap proses pembelajaran dan sulitnya tercapai tujuan pembelajaran, siswa akan merasa gelisah, resah, bosan dan jenuh. Sebaliknya dengan iklim kelas yang kondusif dan menarik dapat dengan mudah mencapai tujuan pembelajaran, dan proses pembelajaran yang dilakukan menyenangkan bagi siswa.

Dalam penelitian ini peneliti memilih SMP Negeri 2 Buay Madang Timur terlihat bahwa nilai rata-rata ulangan harian semester ganjil pada mata pelajaran IPS Terpadu menghasilkan nilai yang kurang memuaskan. Karena di SMP Negeri 2 Buay Madang Timur standar nilai ketuntasan belajar yang harus dicapai oleh siswa adalah 71. Dari permasalahan diatas dapat dilihat bahwa penciptaan iklim kelas yang kondusif sangat mendukung untuk terlaksananya proses belajar mengajar yang baik, sehingga akan memunculkan sikap belajar yang baik pula pada diri siswa. Keras atau 


\section{Pengaruh Iklim Kelas Kondusif Dalam Pembelajaran Ips Terhadap Hasil Belajar Siswa Kelas Viii Di Smp N 2 Buay Madang Timur}

tidaknya usaha belajar peserta didik bergantung pada besar tidaknya penciptaan iklim kelas yang kondusif. Demi suksesnya belajar, iklim kelas itu haruslah kuat dan saling mendukung. Untuk itu, penciptaan iklim kelas harus kondusif karena siswa akan menjadi sadar bahwa ia harus dapat mencapai tujuan belajarnya, yaitu untuk mendapatkan hasil belajar yang maksimal.

\section{METODE}

Dalam penelitian ini, metode yang digunakan adalah metode eksperimen. Metode eksperimen yaitu metode penelitian yang di gunakan untuk mencari pengaruh terhadap yang lain dalam kondisi yang terkendalikan (Sugiyono, 2017:72). Dengan menggunakan pendekatan deskriptif kuantitatif, subjek dalam penelitian ini meliputi siswa kelas VIII A sebagai kelas eksperimen dan kelas VIII B sebagai kelas kontrol yang berjumlah 42. Pengambilan sampel dengan cara acak tanpa memperhatikan strata dari populasi itu. Alat pengumpulan data dalam penelitian ini adalah angket dan tes.

Metode analisis deskriptif menggunakan Statistik deskriptif (Sugiyono, 2013). Teknik analisis data menggunakan analisis regresi linier sederhana dengan rumus sebagai berikut:

$$
\hat{Y}=a+b \bar{X}
$$

Sumber : Sugiyono (2017: 188)

$$
\begin{aligned}
& a=\frac{\sum Y-B \sum X}{n} \\
& b=\frac{n \sum X Y-\left(\sum X\right)\left(\sum Y\right)}{n \sum X^{2}-\left(\sum X\right)^{2}}
\end{aligned}
$$

Seanjutnya untuk pengujian hipotesis menggunakan uji t dapat dilakukan dengan menggunakan rumus sebagai berikut:

$$
t_{=} \frac{r \sqrt{n-2}}{\sqrt{1-r^{2}}} \quad \text { (Sugiyono, 2017: 184) }
$$

Keterangan:

$t=$ nilai t hitung

$r=$ besarnya koefisien

$n=$ jumlah sampel 


\section{HASIL DAN PEMBAHASAN}

\section{Hasil}

Pembentukan iklim kelas kondusif dalam pembelajaran IPS dalam penelitian ini adalah suasana yang aman, nyaman, dan menyenangkan. Dengan iklim belajar yang kondusif tersebut dapat membuat siswa merasa nyaman dalam belajar yang pada akhirnya dapat membangkitkan gairah dan semangat siswa dalam belajar, maka dapat memberikan dampak positif dalam mencapai nilai maksimal. Begitu juga sebaliknya, iklim kelas yang tidak kondusif membuat siswa merasa bosan dan tidak semangat dalam belajar sehingga nilai pun kurang memuaskan. Penciptaaan iklim kelas kondusif mempunyai beberapa indikator berdasarkan observasi langsung yang peneliti lakukan, indikator penciptaan iklim kelas kondusif dalam pembelajaran IPS di kelas VIII SMP Negeri 2 Buay Madang Timur Tahun Ajaran 2018/2019 adalah sebagi berikut: 1) Suasana pembelajaran IPS di kelas yaitu dengan iklim kelas yang tertib, tenang, jauh dari kegaduhan dan kekacauan. 2) Hubungan antar warga kelas yaitu adanya hubungan yang akrab, hangat, penuh pengertian, dan rasa kekeluargaan antara siswa dengan guru, maupun siswa dengan siswa. 3) Aktifitas belajar mengajar yaitu ditandai keaktifan siswa yang tinggi didalam kelas dan semangatnya guru dalam mentransformasikan pengetahuannya pada siswa. 4) Kondisi fisik, kerapian dan kebersihan ruang kelas yaitu penataan meja dan kursi serta perlengkapan lainnya yang terdapat di kelas. 5) Kedisiplinan siswa didalam kelas yaitu semua kegiatan sekolah diatur dengan tertib, dilaksanakan dan dilakukan dengan penuh tanggung jawab dan merata.

Berdasarkan hasil observasi juga sudah terlihat bahwa sudah ada usaha dari pihak guru terutama guru mata pelajaarn IPS Terpadu dalam menciptakan suasana belajar yang aman, nyaman, tertib dan menyenangkan seperti: memberikan motivasi kepada siswa agar siswa lebih giat belajar, memberikan teguran pada siswa yang menggangu siswa yang lain dalam belajar, menunjukkan sikap yang akrab dengan cara memberikan teguran dengan sapaan yang menyenangkan, menciptakan hubungan yang harmonis, memberikan kesempatan pada siswa bertanya pada saat proses belajar mengajar berlangsung. Hasil belajar merupakan suatu perolehan perilaku untuk membantu kecakapan, kebiasaan, sikap, penguasaan dan penghargaan dalam individu belajar. Jadi, hasil belajar adalah kemampuan siswa dalam menguasai teori atau materi yang ditunjukkan dari ulangan harian siswa mata 


\section{Pengaruh Iklim Kelas Kondusif Dalam Pembelajaran Ips Terhadap Hasil Belajar Siswa Kelas Viii Di Smp N 2 Buay Madang Timur}

pelajaran IPS Terpadu Kelas VIII A B SMP Negeri 2 Buay Madang Timur tahun ajaran 2018/2019.

\section{Pembahasan}

Dalam penelitian ini menggunakan analisis deskriptif persentase dengan hasil sebagai berikut :

Tabel 1.

Persentase Hasil Angket Iklim Kelas Kondusif Setiap Kategori

\begin{tabular}{|c|c|c|c|}
\hline Iklim Kelas Kondusif & Skor & Frekuensi (f) & Presentase (\%) \\
\hline Tinggi & $>69,54$ & 7 & $16,67 \%$ \\
Sedang & $52,12-69,54$ & 30 & $71,43 \%$ \\
Rendah & $<52,12$ & 5 & $11,09 \%$ \\
\hline \multicolumn{2}{|c|}{ Jumlah } & $\mathbf{4 2}$ & $\mathbf{1 0 0} \%$ \\
\hline
\end{tabular}

Tabel 2.

Persentase Hasil Belajar Siswa Setiap Kategori

\begin{tabular}{|c|c|c|c|}
\hline Hasil Belajar Siswa & Skor & Frekuensi (f) & Presentase (\%) \\
\hline Tinggi & $>80,37$ & 3 & $7,14 \%$ \\
Sedang & $50,59-80,37$ & 32 & $76,19 \%$ \\
Rendah & $<50,59$ & 7 & $16,67 \%$ \\
\hline \multicolumn{2}{|c|}{ Jumlah } & $\mathbf{4 2}$ & $\mathbf{1 0 0} \%$ \\
\hline
\end{tabular}

Dari tabel 1 menunjukkan bahwa iklim kelas kondusif dalam pembelajaran IPS kelas VIII di SMP Negeri 2 Buay Madang Timur adalah berkategori sedang. Hal tersebut dibuktikan dari perolehan skor sebesar $71,43 \%$ dari hasil angket yang menjawab iklim kelas kondusif berkategori sedang. Sementara sisanya menjawab dalam kategori tinggi dan rendah dengan perolehan nilai rata-rata hasil angket 60,83 dan standar deviasi 8,71.

Sedangkan dari tabel 2 menunjukkan bahwa hasil belajar siswa kelas VIII di SMP Negeri 2 Buay Madang Timur adalah berkategori sedang. Hal tersebut dibuktikan dari perolehan skor sebesar dari hasil tes soal 76,19 \% yang menjawab berkategori sedang. Sementara sisanya menjawab dalam kategori tinggi dan rendah dengan perolehan nilai rata-rata hasil tes 65,48 dan standar deviasi 14,89 . 
Wiastuti Rahayu Ningsih ${ }^{1}$, Mursilah $^{2}$, Vovi Sinta $^{3}$

Tabel. 3

Penolong perhitungan Koefisien Regresi dan Korelasi

\begin{tabular}{|c|c|c|c|c|c|}
\hline No & $X$ & $\mathbf{Y}$ & $x^{2}$ & $X Y$ & $\mathbf{Y}^{2}$ \\
\hline 1 & 61 & 45 & 3.721 & 2.745 & 2.025 \\
\hline 2 & 58 & 55 & 3.364 & 3.190 & 3.025 \\
\hline 3 & 50 & 60 & 2.500 & 3.000 & 3.600 \\
\hline 4 & 51 & 50 & 2.601 & 2.550 & 2.500 \\
\hline 5 & 58 & 70 & 3.364 & 4.060 & 4.900 \\
\hline 6 & 78 & 70 & 6.084 & 5.460 & 4.900 \\
\hline 7 & 54 & 25 & 2.916 & 1.350 & 625 \\
\hline 8 & 57 & 75 & 3.249 & 4.275 & 5.625 \\
\hline 9 & 59 & 75 & 3.481 & 4.425 & 5.625 \\
\hline 10 & 60 & 75 & 3.600 & 4.500 & 5.625 \\
\hline 11 & 78 & 95 & 6.084 & 7.410 & 9.025 \\
\hline 12 & 60 & 70 & 3.600 & 4.200 & 4.900 \\
\hline 13 & 70 & 80 & 4.900 & 5.600 & 6.400 \\
\hline 14 & 48 & 70 & 2.304 & 3.360 & 4.900 \\
\hline 15 & 56 & 45 & 3.136 & 2.520 & 2.025 \\
\hline 16 & 53 & 45 & 2.809 & 2.385 & 2.025 \\
\hline 17 & 59 & 55 & 3.481 & 3.245 & 3.025 \\
\hline 18 & 64 & 60 & 4.096 & 3.840 & 3.600 \\
\hline 19 & 61 & 95 & 3.721 & 5.795 & 9.025 \\
\hline 20 & 38 & 55 & 1.444 & 2.090 & 3.025 \\
\hline 21 & 65 & 55 & 4.225 & 3.575 & 3.025 \\
\hline 22 & 66 & 65 & 4.356 & 4.290 & 4.225 \\
\hline 23 & 74 & 90 & 5.476 & 6.660 & 8.100 \\
\hline 24 & 67 & 45 & 4.489 & 3.015 & 2.025 \\
\hline 25 & 52 & 60 & 2.704 & 3.120 & 3.600 \\
\hline 26 & 58 & 65 & 3.364 & 3.770 & 4.225 \\
\hline 27 & 40 & 40 & 1.600 & 1.600 & 1.600 \\
\hline 28 & 67 & 75 & 4.489 & 5.025 & 5.625 \\
\hline 29 & 58 & 60 & 3.364 & 3.480 & 3.600 \\
\hline 30 & 60 & 65 & 3.600 & 3.900 & 4.225 \\
\hline 31 & 72 & 80 & 5.184 & 5.760 & 6.400 \\
\hline 32 & 64 & 70 & 4.096 & 4.480 & 4.900 \\
\hline 33 & 54 & 55 & 2.916 & 2.970 & 3.025 \\
\hline 34 & 68 & 80 & 4.624 & 5.440 & 6.400 \\
\hline 35 & 67 & 75 & 4.489 & 5.025 & 5.625 \\
\hline 36 & 62 & 70 & 3.844 & 4.340 & 4.900 \\
\hline 37 & 71 & 80 & 5.041 & 5.680 & 6.400 \\
\hline 38 & 61 & 70 & 3.721 & 4.270 & 4.900 \\
\hline 39 & 56 & 55 & 3.136 & 3.080 & 3.025 \\
\hline 40 & 63 & 70 & 3.969 & 4.410 & 4.900 \\
\hline 41 & 71 & 80 & 5.041 & 5.680 & 6.400 \\
\hline 42 & 66 & 75 & 4.356 & 4.950 & 5.625 \\
\hline$\Sigma$ & 2.555 & 2.750 & 158.539 & 170.520 & 189.150 \\
\hline
\end{tabular}

Sumber: Data o olah Peneliti 


\section{Pengaruh Iklim Kelas Kondusif Dalam Pembelajaran Ips Terhadap Hasil Belajar Siswa Kelas Viii Di Smp N 2 Buay Madang Timur}

Berdasarkan tabel 3 dan hasil perhitungan peneliti diperoleh persamaan

analisis regresi sederhana yaitu : $\hat{\mathrm{Y}}=a+b X$

$$
\hat{\mathrm{Y}}=2,32+1,04 X
$$

Dengan hasil perhitungan menggunakan product moment maka diperoleh korelasi sebesar 0,607 yang berarti bahwa adanya hubungan yang cukup signifikan antara iklim kelas kondusif dengan hasil belajar siswa. Untuk hasil perhitungan uji hipotesis diperoleh sebesar $\mathrm{t}_{\text {hitung }}=4,83>\mathrm{t}_{0,05 ; 40}=1,68$ maka $\mathrm{H}_{0}$ ditolak dan $\mathrm{Ha}$ diterima yang berarti iklim kelas kondusif dalam pembelajaran IPS mempunyai pengaruh yang sangat signifikan terhadap hasil belajar siswa kelas VIII di SMP N 2 Buay Madang Timur

\section{SIMPULAN}

Berdasarkan data hasil penelitian diperoleh kesimpulan bahwa adanya pengaruh iklim kelas kondusif dalam pembelajaran IPS terhadap hasil belajar siswa kelas VIII di SMP N 2 Buay Madang Timur. Hal ini diketahui dari hasil teknik analisis data sebagai berikut :

1. Iklim kelas kondusif dalam pembelajaran IPS siswa kelas VIII di SMP N 2 Buay Madang Timur dengan hasil perhitungan analisis deskriptif berkategori sedang, karena perolehan skor hasil angket yang menunjukkan bahwa dari 42 siswa terdapat 7 siswa atau 16,67 \% menjawab iklim kelas kondusif dalam kategori tinggi, sedangkan 30 siswa atau 71,43\% menjawab iklim kelas kondusif dalam kategori sedang, sedangkan 5 siswa atau 11,90 \% menjawab iklim kelas kondusif dalam kategori rendah dengan nilai rata-rata hasil angket 60,83 dan standar deviasi 8,71.

2. Hasil belajar siswa kelas VIII di SMP N 2 Buay Madang Timur dengan hasil perhitungan analisis deskriptif berkategori sedang, karena perolehan skor hasil tes yang menunjukkan bahwa dari 42 siswa terdapat 3 siswa atau 7,14 \% menjawab hasil belajar dalam kategori tinggi, sedangkan 32 siswa atau 76,19\% menjawab hasil belajar dalam kategori sedang, sedangkan 7 siswa atau 16,67\% menjawab hasil belajar dalam kategori rendah dengan nilai rata-rata hasil tes 65,48 dan standar deviasi 14,89 . 
Wiastuti Rahayu Ningsih ${ }^{1}$, Mursilah $^{2}$, Vovi Sinta ${ }^{3}$

3. Dengan hasil perhitungan teknik analisis data diketahui bahwa t hitung sebesar 4,83 dan harga t tabel untuk taraf signifikasi $5 \%$ yaitu 1,68. Dapat disimpulkan bahwa $\mathrm{t}_{\text {hitung }}=4,83>\mathrm{t}_{0,05 ; 40}=1,68$ maka $\mathrm{H}_{0}$ ditolak dan Ha diterima, yang berarti bahwa iklim kelas kondusif dalam pembelajaran IPS mempunyai pengaruh yang signifikan terhadap hasil belajar siswa kelas VIII di SMP N 2 Buay Madang Timur.

\section{UCAPAN TERIMAKASIH}

Terimakasig d ucapkan kepada Program Pendidikan Ekonomi dan juga kepada seluruh pihak yang telah ikut serta dalam pembuatan skripsi penulis. Kepada kedua orang tua dan kedua pembimbing penulis, serta teman-teman seperjuangan yang telah menorehkan banyak cerita dan juga pengalaman. Terimakasih juga kepada tim Journal UTILITY STKIP Nurul Huda.

\section{REFERENSI}

Ardy Wiyani, Novan.2016.Manajemen Kelas Teori Dan Aplikasi Untuk Menciptakan Kelas Yang Kondusif. Jogjakarta. Ar-Ruzz Media

Chamidah, Nur. 2014. Pengaruh Pengelolaan Kelas Terhadap Prestasi Belajar IPS Siswa Kelas IV SD Negeri Margoyasan Yogyakarta. Skripsi. Fakultas IImu Pendidikan: Universitas Negeri Yogyakarta.

Fiteriani, I. (2015). Membudayakan Iklim Semangat Belajar pada Siswa Sekolah Dasar. TERAMPIL: Jurnal Pendidikan dan Pembelajaran Dasar, 2(1), 115-25.

Gandra Irawan, Oskar. 2014. Pengaruh Iklim Belajar Yang Kondusif Terhadap Hasil Belajar Siswa Mata Pelajaran IPS Terpadu di SMP. Jurnal: Universitas Tanjungpura Pontianak

Hapsari, Widyaning. 2017. Korelasi Antara Iklim Kelas Dan Kemandirian Belajar Dengan Kemampuan Berpikir Kreatif Pada Mahasiswa Matematika Universitas Muhammadiyah Purworejo. Journal The 5th Urecol Proceeding: Universitas Muhammadiyah Purworejo.

Mustafida, F. (2017). Strategi Menciptakan Kelas yang Kondusif di SD/MI (Sebuah kajian pedagogis, psikologis). Jurnal Madrasah. UIN Malang.

Sanjaya, W. (2015). Perencanaan dan desain sistem pembelajaran. Kencana. 


\section{Pengaruh Iklim Kelas Kondusif Dalam Pembelajaran Ips Terhadap Hasil Belajar Siswa Kelas Viii Di Smp N 2 Buay Madang Timur}

Indonesia, P. R. (2003). Undang-Undang Republik Indonesia Nomor 20 Tahun 2003 Tentang Sistem Pendidikan Nasional. 